Article

\title{
Assessment of Effective Seasonal Downscaling of TRMM Precipitation Data in Peninsular Malaysia
}

\section{Mohd Rizaludin Mahmud ${ }^{1, *}$, Shinya Numata ${ }^{1}$, Hiroshi Matsuyama ${ }^{1}$,Tetsuro Hosaka ${ }^{1}$ and Mazlan Hashim ${ }^{2}$}

1 Graduate School of Urban Environmental Sciences, Tokyo Metropolitan University, 1-1 Minami Osawa, 192-0397 Hachioji, Tokyo, Japan; E-Mails:nmt@tmu.ac.jp (S.N.); matuyama@tmu.ac.jp (H.M.); hosaka-t@tmu.ac.jp (T.H.)

2 Institute of Geospatial Technology, Universiti Teknologi Malaysia, 81310 Skudai, Johor Bharu, Malaysia; E-Mail: mazlanhashim@utm.my

* Author to whom correspondence should be addressed; E-Mail: rizal.mahmud@gmail.com; Tel.: +81-42-677-1111; Fax: +81-42-677-2665.

Academic Editors: Ioannis Gitas and Prasad S. Thenkabail

Received: 6 November 2014 / Accepted: 26 March 2015 / Published: 7 April 2015

\begin{abstract}
Precise spatio-temporal measurements of rainfall during seasonal monsoons are critical for accurate hydrologic analyses in the tropical regions of Southeast Asia. The use of satellite precipitation data is technologically sound but requires downscaling to minimize inherent uncertainties. The uncertainties at a local climate regime that are essential to be resolved are rarely reported; consequently, such work needs attention. To address this problem, we validated the Tropical Rainfall Measuring Mission (TRMM) precipitation data using high-resolution areal precipitation $(0.125 \mathrm{deg}$.) at a seasonal scale. This study examined the performance of the monthly rainfall data product (TRMM 3B43) at the seasonal monsoon scale in the local climate region of Peninsular Malaysia. The high-resolution areal precipitation data $(0.125$ deg.) were derived from a dense rain gauge network ever collected in Peninsular Malaysia $(n=984)$. Three relevant performance elements were evaluated: (i) the ability to depict temporal rainfall variation (ii) the quantitative error between TRMM and ground rainfall; and (iii) the ability to estimate the actual rainfall amount. We found that the ability of monthly TRMM data to depict rainfall variation and its tendency to propagate large errors varied seasonally. The correlation between TRMM and ground rainfall was good during the wettest period in all local climate regions. The error was related to the northeast monsoon and inter-monsoon 2 (September-October). Meanwhile, the TRMM ratio varied
\end{abstract}


regionally, rather than seasonally. Determining the local-scale uncertainties will facilitate future downscale activities using TRMM satellite data in this region.

Keywords: TRMM; monsoon seasons; high resolution areal precipitation; small region

\section{Introduction}

Precise seasonal monsoon rainfall measurement is critical for accurate hydrologic prediction, simulation, and assessment in humid tropical regions. Using Tropical Rainfall Measuring Mission (TRMM) satellite precipitation data as an alternative to conventional rain gauge measurement is one useful option [1,2]. Despite its promising potential for many regions worldwide [3-7], its sensitivity for local-scale rainfall in a small region, particularly one located in Southeast Asia, is contentious due to inherent uncertainties. These uncertainties include the effect of upscaling the instantaneous rain rate to an effective temporal scale [8], the insensitivity of the TRMM precipitation algorithms to low- and high-precipitation clouds [9,10], and the coarse grid size of the TRMM data for resolving local rainfall patterns [11].Prompt actions must be taken to mitigate these uncertainties in order to obtain improved rainfall estimates from the TRMM data that suit local scale applications. In general, the untreated TRMM data showed an increasingly biased result when forced to scale hydrology modeling down to the local level as the region size decreased from large [12] to medium [13] to small [14].

An effective countermeasure to mitigate these uncertainties can be achieved through downscaling, which can be defined as the specific process that improves the sensitivity of satellite precipitation data to local rainfall properties. In the case of Peninsular Malaysia, improving the coarse resolution of the TRMM data and minimizing the quantitative seasonal error from the rainfall estimates are essential for obtaining precise seasonal rainfall information due to its small size and the high rainfall excess. Having detailed information on TRMM uncertainties at a finer scale can be useful for developing and applying suitable downscale procedures for specific local areas. Since ideal downscaling is designed for a specific environmental niche (e.g., $[15,16]$ ), having an intensive reference would reduce the laborious processing work and increase its efficiency.

Unfortunately, previous validations or related TRMM studies in this region were unable to provide the necessary information for seasonal downscaling. These include the inability to depict the spatial error distribution and correlation due to the use of discrete rain-gauge comparisons [9,11] and coarse-grid resolution [8]. In addition, the reported uncertainties were measured in instantaneous scale and expected to increase as the instantaneous rain rate is upscaled [17]. Moreover, because TRMM data products and validation scope varied among previous studies, the generalization of these findings for specific local-scale application is difficult and inappropriate. This is due to differences in the processing scheme, spatial grid size, and temporal scale of the rainfall measurement (hourly, daily, monthly) of the data products. Hence, the uncertainties in the TRMM products were different even within similar regions $[18,19]$.

A suitable method to determine the detailed uncertainties for this region is through meticulous validation conducted using a high-resolution precipitation grid within the local climate scale. This is because the rainfall intensity varies between monsoon seasons and within a local rainfall region [20]. 
The effects of local environmental factors on rainfall, including topography, prevailing local winds, and maritime effects [21,22], are significant. Furthermore, from the perspective of catchment hydrology, the size of the effective catchment for water resources in this region is relatively small [23].The grid-based assessment was able to report a comprehensive spatial-based uncertainties distribution that is useful for local scale application $[12,19]$. Nonetheless, there are few intensive spatial-based seasonal uncertainties reports for this region. Therefore, as a preliminary step for effective downscaling, a thorough validation is needed. With the launch of the TRMM successor, the Global Precipitation Mission (GPM) [24], there is a bright prospect for the active use of satellite precipitation and this downscaling gap should be accomplished.

This paper validated the re-gridded TRMM precipitation data at a local climate scale in a small, humid tropical region. The monthly rainfall estimates derived from the TRMM 3B43 was evaluated at the seasonal monsoon scale in the local climate region of Peninsular Malaysia using high-resolution areal precipitation data $\left(0.125^{\circ}\right)$. The areal rainfall was derived from a dense rain gauge network $(n=984)$. Four relevant performance elements were evaluated: (i) the ability to depict temporal rainfall variation (measured using the correlated ground data); (ii) the quantitative error between the TRMM and ground rainfall (measured using the root mean square error (RMSE)); (iii) the ability to estimate the actual rainfall amount (measured using the ratio between TRMM and actual rainfall), and (iv) the relative ability to reproduce ground rain gauge observations (measured using the Nash-Sutcliffe efficiency).

\section{Materials and Methods}

\subsection{Study Site}

Peninsular Malaysia (98.7-104.5 E, 1.1-7.5 N) is located in the western part of Malaysia (Figure 1). It has a population of 18 million and covers approximately $132,000 \mathrm{~km}^{2}$. The general land cover is agriculture (52\%), forest (22\%), and built up areas (26\%) [25]. The climate is humid tropical with temperatures ranging from 24 to $32{ }^{\circ} \mathrm{C}$ and rainfall throughout the year, with a total annual rainfall of $1200 \mathrm{~mm}$. The rainfall distribution pattern over Peninsular Malaysia is strongly influenced by regional wind flows [19]; therefore, it is important to describe it based on the seasonal monsoon flows. A combination of the Asian Monsoon flows and local topographic patterns classified the area into five local climate regions; (i) northwest; (ii) east; (iii) west; (iv) southwest and (v) highland (>400 m a.s.1.) (Figure 2). Two distinct wet seasons run from November to February, during which the northeast monsoon (NEM) produces heavy rainfall in the east region; and from May until mid-September, when the southwest monsoon (SWM) affects some areas in the west and southwest regions (Figure 1). The northwest, west, and southwest regions experience two wet seasons per year, from mid-March until May (IM1) and from October until November (IM2); both are in the inter-monsoon period [26]. These two subsequent inter-monsoon periods take place during the shifting of the primary NEM and SWM seasons and vice versa. Due to the change of wind direction and effect of local topography, substantial rainfall occurred. 

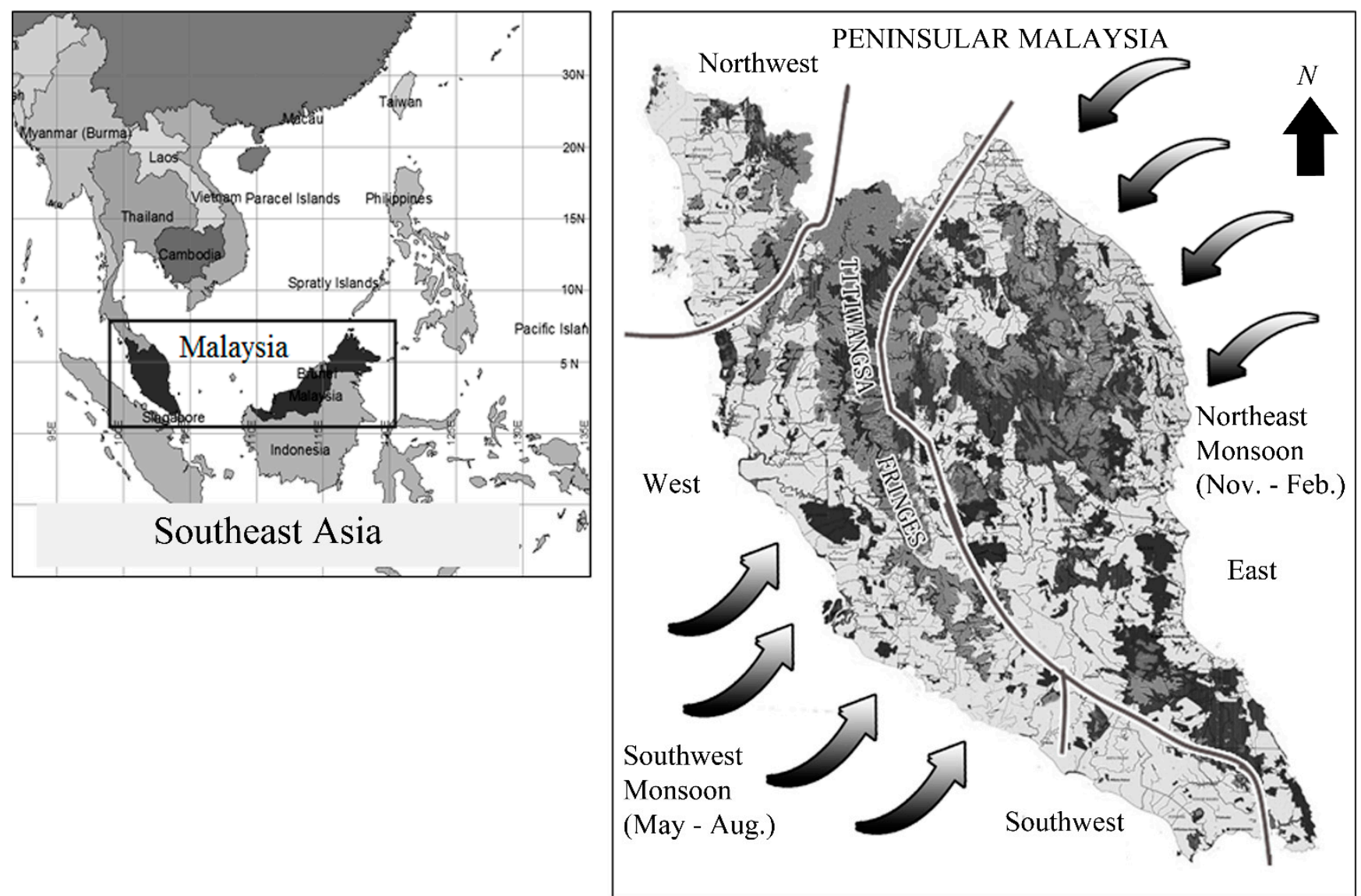

Figure 1. The study area.

\subsection{Data}

\subsubsection{TRMM Satellite Precipitation Data}

Precipitation data product from the TRMM satellite, namely TRMM 3B43 Version 6 was used for the following reasons: (i) frequent and consistent data collection (daily scale up to monthly scale); (ii) high spatial resolution $\left(0.25^{\circ}\right)$; and (iii) public domain data access. The high spatial and temporal resolution of this data satisfies the requirement to be used as the primary input for hydrological modeling and spatial analysis. In this study, the raw TRMM 3B43 data product provided a monthly average rain rate, which was originally computed from the three hourly daily basis rain rate estimates. The data are accessible online at http://daac.gsfc.nasa.gov/data/datapool/TRMM/01_Data_Products/02_Gridded/ index.html. The TRMM data were downloaded from the public domain host on the World Wide Web. A total of 156 monthly rain rate images were downloaded, covering the13 year period from 1998 . We compared the TRMM 3B43 version 6 and the latest version 7 and found no significant difference between them (Appendix).

\subsubsection{Rain Gauge Data}

A total of 984 rain gauges, covering the entire Peninsular Malaysia, were collected from the Malaysia Department of Irrigation and Drainage and used in this study (Figure 2). Vast amounts of rain gauge data are collected to provide high-resolution areal rainfall information on the ground at both spatial and 
temporal scales. The rain gauge measurement was conducted on a daily basis with $24 \mathrm{~h}$ observation from 8.00 a.m. until 8.00 a.m. of the next day (based on Malaysian Standard Time). The daily rainfall measurement was then totaled for a one month period to produce the monthly basis rainfall measurement. This data and its corresponding geographical coordinates was then exported into geographic information system (GIS) shapefile format.

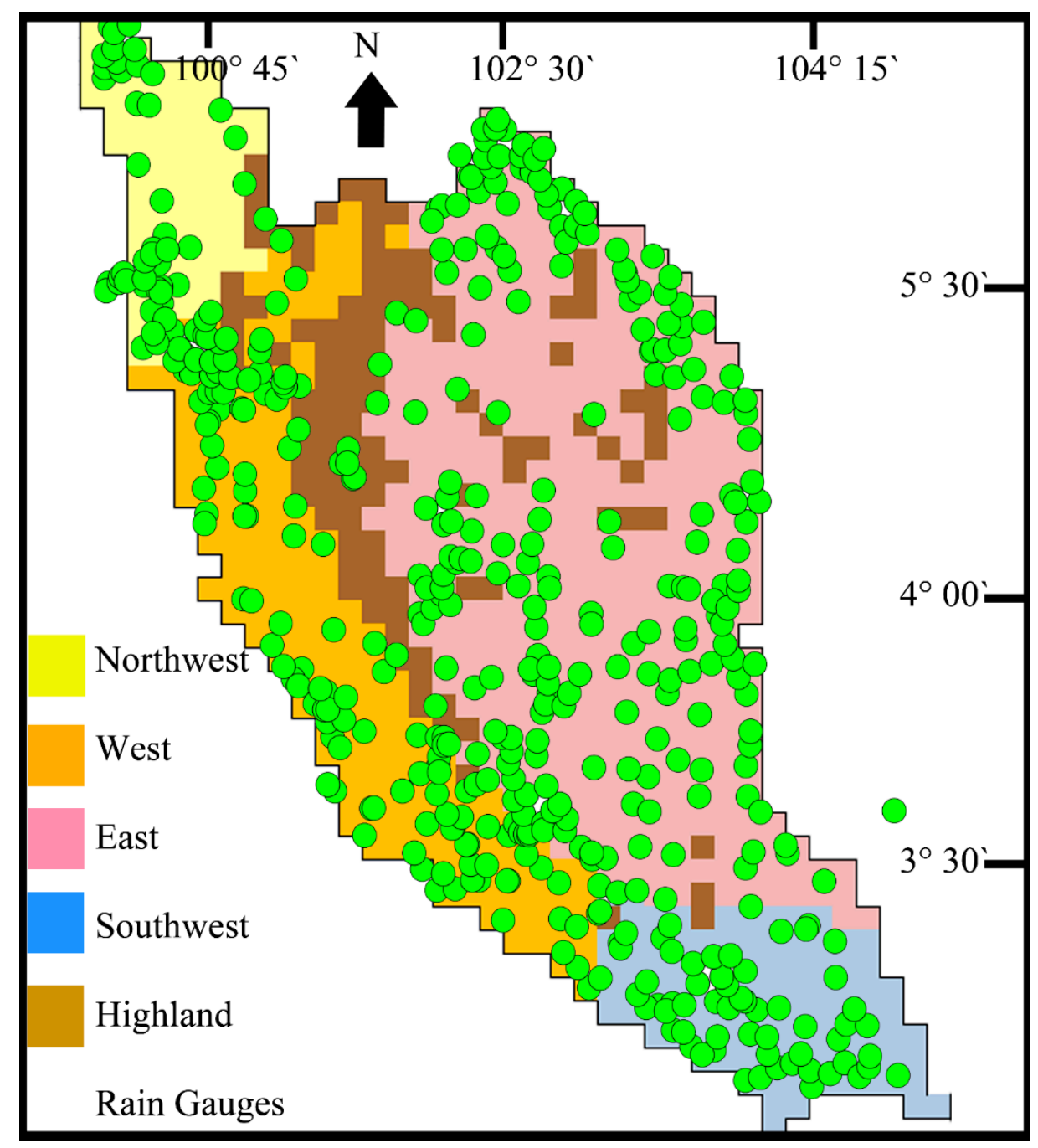

Figure 2. Peninsular Malaysia climate region at 0.125 degrees and distribution of rain gauges.

\subsection{Methodology}

\subsubsection{Direct Re-gridding of the TRMM Monthly Rainfall Estimation}

The TRMM data for the experimental site were extracted from the global dataset and projected into a local coordinates system. The monthly rain rate estimates from the TRMM 3B43 data were converted into monthly rainfall estimates by multiplying the hours and the number of days in each month. These are the standard processing procedures as stated in the standard TRMM Spatial Data Information and Management Systems (TSDIS) for raw rain rate data version 6 [27]. The basic equation of this estimation is given below (Equation (1)). After the monthly rainfall estimates are computed, the initial grid of TRMM 3B43 was rescaled to a finer grid of $0.125^{\circ}$. The new rainfall estimate values are obtained using 
the nearest neighbor interpolation scheme. The nearest neighbor interpolation scheme is selected due to two reasons; (i) minimization of the effects of smoothing which may lead to generalization of the rainfall patterns; and (ii) because the size of each pixel of the TRMM precipitation data is constant, nearest neighbor interpolation is able to retain the original rainfall values when rescaled.

$$
R_{\text {sat }}=R s \times D m \times H t
$$

where $R_{\text {sat }}$ is the monthly TRMM rainfall estimate, $R s$ is the hourly average rain rate in a particular month, $D m$ is total days per month, and $H t$ is the total hours per day which is set as a constant of 24 .

\subsubsection{Generation of Gridded Areal Rainfall from Rain Gauge Data}

Rainfall data from a total of 984 rain gauges were used to generate gridded areal precipitation surfaces at $0.125^{\circ}$ resolution. That is a four-times areal increment of the initial TRMM areal grid $\left(0.25^{\circ}\right)$. This rain gauge data was interpolated using the co-Kriging interpolation scheme, which is commonly used for creating areal rainfall [28]. Cross-validation is conducted to determine the reliability of the interpolated areal rainfall surfaces. Two independent datasets were established, one used as a reference, the other used as a tester. The root mean square error (RMSE) and its mean percentage error (MAPE) are computed and then used as cross-validation metrics.

\subsubsection{Validation on TRMM Rainfall against Gridded Areal Rainfall}

Three statistical indicators were used in this study, (i) Pearson correlation (r); (ii) average ratio between TRMM estimates and rain gauge measurements; and (iii) root mean square error (RMSE). Linear regression was used to examine the strength of the linear relationship between TRMM rainfall estimates and rain gauge measurements. High correlation values indicated a high ability of TRMM to describe seasonal rainfall variation. The ratio between the TRMM precipitation estimates and the corresponding rain gauge measurement provides information on the capability of TRMM to describe the actual rainfall on the ground. Ratio values $>1$ indicated an overestimation in the TRMM data, while those $<1$ indicated an underestimation. A value of 1 indicated that TRMM estimated the actual rainfall perfectly. The RMSE was used to quantify the TRMM and rain gauge data in standard SI units (mm). In order to provide standardized TRMM-rain gauge validation across areas and seasons with different base rainfall rates, Nash-Sutcliffe efficiency (NSE) was used. NSE value of 1 indicates TRMM agrees with rain gauge observations, while value of 0 means that TRMM is only as good as always predicting the mean observed precipitation value. Equations (2)-(5) are the standard equations used in this assessment for all indicators.

$$
\begin{gathered}
r=\frac{n\left(\sum R_{\text {sat }}\right)-\left(\sum R_{\text {sat }}\right)\left(\sum R_{r g}\right)}{\sqrt{\left[n \sum R_{\text {sat }}{ }^{2}-\left(\sum R_{\text {sat }}\right)^{2}\right]\left[\sum R_{r g}-\left(\sum R_{r g}\right)^{2}\right]}} \\
t=\frac{1}{n} \frac{\sum R_{\text {sat }}}{\sum R_{\text {rg }}} \\
s_{e}=\sqrt{\frac{\sum\left(R_{\text {sat }}-R_{r g}\right)^{2}}{n}}
\end{gathered}
$$




$$
N S E=1-\frac{\left\langle\left(R_{r g}-R_{\text {sat }}\right)^{2}\right\rangle}{\left\langle\left(R_{r g}-\left(R_{r g}\right)\right)^{2}\right\rangle}
$$

where $r$ is the Pearson's correlation co-efficient, $t$ is the ratio between TRMM estimates over rain gauge measurements, $S e$ is the RMSE, $R_{s a t}$ is the monthly TRMM rainfall estimate, $R_{r g}$ is the monthly rain gauge data, and $n$ is the number of samples, <.> represent the averages.

All four statistical indicators were computed for every corresponding pixel of both rainfall datasets from 1998 to 2010. The spatial assessment was conducted at all five local climate regions: northwest, east, west, southwest, and high elevated terrain during four major monsoon seasons including NEM, IM1, SWM and IM2. Auxiliary information regarding seasonal average rainfall variation and the co-efficient of variation (COV) from all rain gauge data were calculated for further analysis of the TRMM correlation, the ratio, and RMSE. These two rainfall characteristics were selected due to inherent characteristics during each monsoon season.

\subsubsection{TRMM Systematic Bias and Subgrid Variation Determination}

The validation is designed to determine the seasonal systematic error of TRMM at the fine grid of $0.125^{\circ}$ resolution. Subsequently, the spatial downscale process may introduce subgrid variation effects. To anticipate this matter, a comparison between the validation results at initial resolution $\left(0.25^{\circ}\right)$ and downscale resolution $\left(0.125^{\circ}\right)$ is carried out. $T$-tests are employed to verify whether the results significantly vary at $95 \%$ confidence level. Significant differences will indicate significant effects of subgrid variation on the validation and vice versa.

\section{Results}

\subsection{TRMM Seasonal Correlation, Ratio, and RMSE for Peninsular Scale}

For the Peninsular Malaysia scale, the TRMM showed good spatial correlation with rain gauge data only during the NEM and IM1 $(>0.65)$ (Table 1). The measurement errors were higher during the NEM and IM2. Overestimates of $70 \%-90 \%$ of actual rainfall measurements were seen in all seasons. Analysis of variance (ANOVA) was conducted with the null hypotheses that there were no significant differences in the statistical indicators within different monsoon seasons. The ANOVA result indicated that the seasonal correlation and RMSE were significantly different among monsoon seasons $\left(\mathrm{F}_{0.05} ; 3,3312=846, \mathrm{~F}_{0.05} ; 3,3312=427\right)$.

Table 1. Average annual scale statistical indicators for the direct transformed Tropical Rainfall Measuring Mission (TRMM) 3B43 data for average Peninsular Malaysia from 1998 to 2010 .

\begin{tabular}{ccccc}
\hline Season & Correlation, $(\mathbf{r})$ & RMSE $(\mathbf{m m})$ & Ratio & NSE \\
\hline NEM & 0.745 & 142 & 1.8 & 0.302 \\
IM1 & 0.651 & 88 & 1.9 & 0.386 \\
SWM & 0.397 & 91 & 1.7 & -0.188 \\
IM2 & 0.406 & 123 & 1.7 & -0.191 \\
\hline
\end{tabular}




\subsection{TRMM Subgrid Variation Analysis}

The comparison between the $0.25^{\circ}$ and $0.125^{\circ}$ grids(Table 2 ) have showed that there was not enough evidence to indicate a significant difference between $0.25^{\circ}$ and $0.125^{\circ}$ analyses (Table 2). However, there were inherent changes in the ratios (Table 2). The ratio for the $0.125^{\circ}$ validation was increased during NEM (7\%) and IM1 (11\%) (Figure 3). During IM1, the ratio increased in all regions except the southwest. By contrast, during the NEM, only the northwest region was affected. Those affected areas experienced the lowest rainfall amount during that season. Based on the cumulative findings of the comparison, we clarified that direct re-gridding of the TRMM data had an imminent effect on the ability of the TRMM to depict spatial rainfall patterns during dry season but had no effect on the overall efficiency and other indicators. Therefore, the $0.125^{\circ}$ validation presented later in this paper is assumed to be the TRMM systematic errors and other related sources (e.g., the post-rainfall estimation algorithm) except for the specific occasions in the spatial rainfall representation (ratio).

Table 2. $T$-test results comparing the $0.250^{\circ}$ and $0.125^{\circ}$ validation results. (a) Correlation; (b) Root mean square error (RMSE); (c) Ratio and (d) Nash-Sutcliffe efficiency (NSE).

(a)

\begin{tabular}{cccccc}
\hline \multirow{2}{*}{ Monsoon Season } & \multicolumn{2}{c}{$\mathbf{0 . 2 5 0}^{\circ}$} & \multicolumn{2}{c}{$\mathbf{0 . 1 2 5}^{\circ}$} & \multirow{2}{*}{-test } \\
\cline { 2 - 5 } & M & SD & M & SD & \\
\hline NEM & 0.738 & 0.118 & 0.745 & 0.122 & ns \\
IM1 & 0.654 & 0.160 & 0.651 & 0.160 & ns \\
SWM & 0.402 & 0.177 & 0.396 & 0.173 & ns \\
IM2 & 0.408 & 0.186 & 0.406 & 0.194 & ns \\
\hline
\end{tabular}

(b)

\begin{tabular}{cccccc}
\hline \multirow{2}{*}{ Monsoon Season } & \multicolumn{2}{c}{$\mathbf{0 . 2 5 0}^{\circ}$} & \multicolumn{2}{c}{$\mathbf{0 . 1 2 5}^{\circ}$} & \multirow{2}{*}{-test } \\
\cline { 2 - 5 } & $\mathbf{M}$ & $\mathbf{S D}$ & $\mathbf{M}$ & $\mathbf{S D}$ & \\
\hline NEM & 141 & 46 & 142 & 47 & $\mathrm{~ns}$ \\
IM1 & 89 & 27 & 88 & 26 & $\mathrm{~ns}$ \\
SWM & 91 & 24 & 91 & 23 & $\mathrm{~ns}$ \\
IM2 & 118 & 40 & 123 & 43 & $\mathrm{~ns}$ \\
\hline
\end{tabular}

(c)

\begin{tabular}{cccccc}
\hline \multirow{2}{*}{ Monsoon Season } & \multicolumn{2}{c}{$\mathbf{0 . 2 5 0}^{\circ}$} & \multicolumn{2}{c}{$\mathbf{0 . 1 2 5}^{\circ}$} & \multirow{2}{*}{-test } \\
\cline { 2 - 5 } & $\mathbf{M}$ & $\mathbf{S D}$ & $\mathbf{M}$ & $\mathbf{S D}$ & \\
\hline NEM & 1.71 & 1.59 & 1.78 & 1.00 & $\mathrm{~ns}$ \\
IM1 & 1.67 & 1.35 & 1.89 & 1.50 & $\mathrm{~ns}$ \\
SWM & 1.68 & 0.77 & 1.68 & 0.67 & $\mathrm{~ns}$ \\
IM2 & 1.64 & 0.97 & 1.66 & 1.25 & $\mathrm{~ns}$ \\
\hline
\end{tabular}

(d)

\begin{tabular}{cccccc}
\hline \multirow{2}{*}{ Monsoon Season } & \multicolumn{2}{c}{$\mathbf{0 . 2 5 0}^{\circ}$} & \multicolumn{2}{c}{$\mathbf{0 . 1 2 5}^{\circ}$} & \multirow{2}{*}{-test } \\
\cline { 2 - 5 } & $\mathbf{M}$ & SD & M & SD & \\
\hline NEM & 0.313 & 0.213 & 0.302 & 0.220 & $\mathrm{~ns}$ \\
IM1 & 0.402 & 0.161 & 0.386 & 0.113 & $\mathrm{~ns}$ \\
SWM & -0.184 & 0.429 & -0.188 & 0.433 & $\mathrm{~ns}$ \\
IM2 & -0.171 & 0.510 & -0.191 & 0.522 & $\mathrm{~ns}$ \\
\hline
\end{tabular}

Note: $\mathrm{M}=$ Mean; $\mathrm{SD}=$ Standard Deviation; $\mathrm{ns}=$ ot significant; $p<0.05$. 

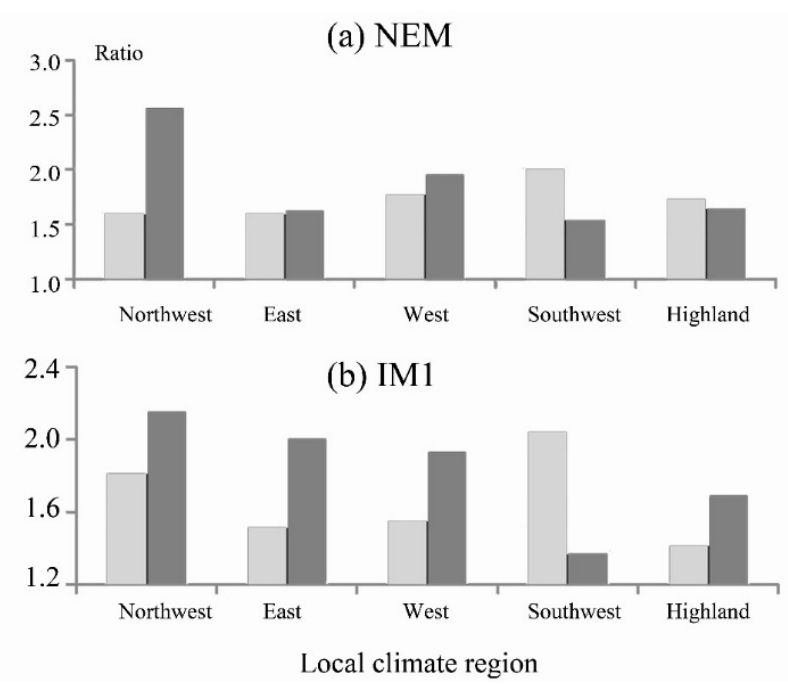

Figure 3. Ratio between 0.25 and 0.125 deg. TRMM-rain gauge validation. (a) Northeast monsoon (NEM); (b) Inter-monsoon 1 (IM1).

\subsection{TRMM Seasonal Correlation in the Local Climate Region}

All the climate regions exhibited a similar trend in the seasonal correlation and significantly varied within seasons (Figure 4). The correlation tended to be high during NEM and IM1 but relatively low during the SWM and IM2; the correlation was highest during NEM (0.60-0.79) followed by IM1 $(0.55-0.70)$, SWM $(0.36-0.50)$ and IM2 (0.30-0.50). This indicates that the ability of TRMM to depict the seasonal rainfall variation during SWM and IM2 was relatively poor compared to that during the other two monsoon seasons. The correlation showed greater variation among regions during SWM and IM2 compared to NEM and IM1 (Figure 5a-d). The correlation during SWM was relatively good in the west and in parts of the southwest, but it was very low for a major part of the east coast (Figure 5c). During IM2, the upper region of Peninsular Malaysia, including the highlands, the upper part of the east coast, and the majority of the northwest had low correlations. A plausible reason for this seasonal influence on the TRMM correlation was caused by the seasonal co-efficient of variation (COV) trend of the ground rainfall (Figure 4). A higher COV was identified during NEM and IM1 than during SWM and IM2, and the seasonal difference was significant $\left(\mathrm{F}_{0.05} ; 3,3312=537\right)$.

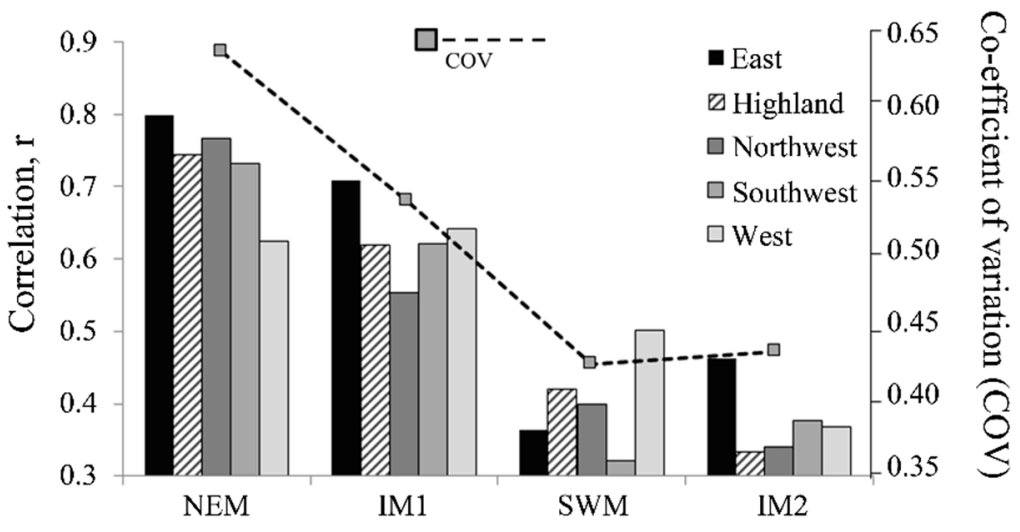

Figure 4. Seasonal correlation of the TRMM 3B43 against ground rainfall at local climate region of Peninsular Malaysia. The line represents the co-efficient of variation (COV) of areal rainfall surfaces. 


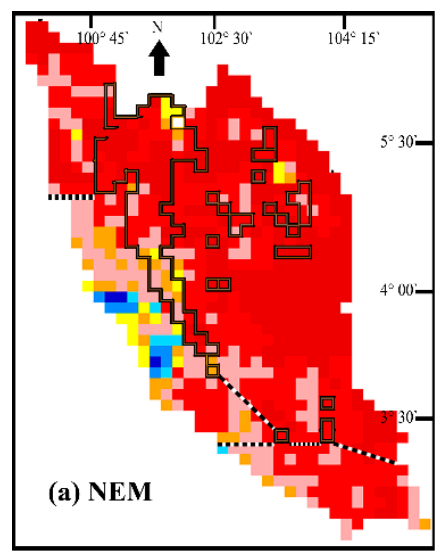

(b) IM1

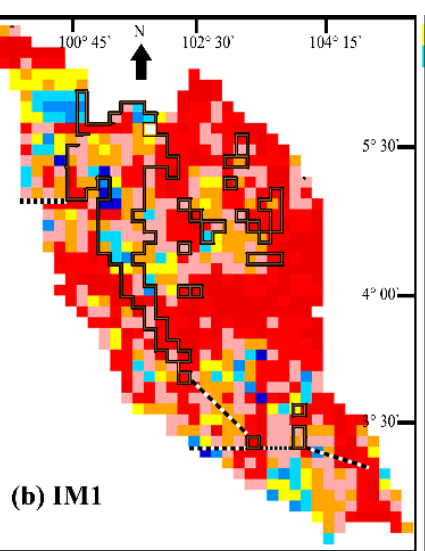

(c) SWM

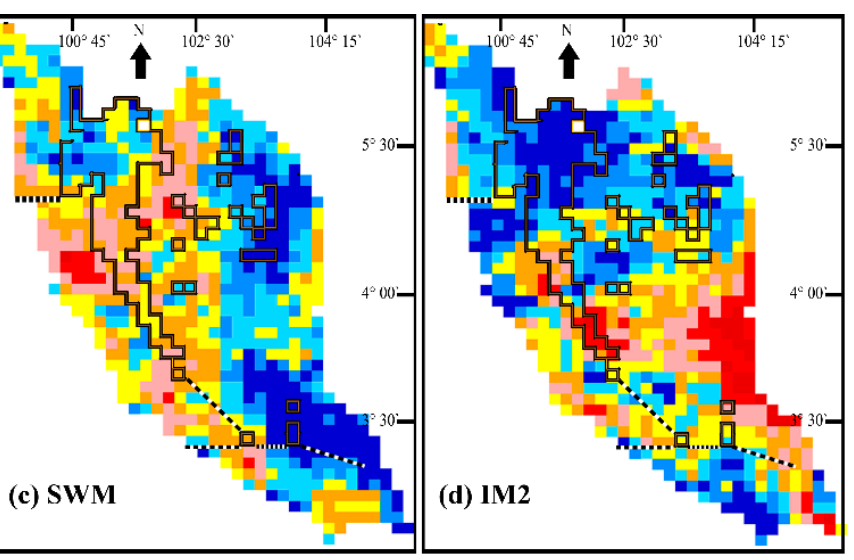

Highland

, u, I Local climate region boundary

Figure 5. Temporal maps of seasonal correlation of the TRMM $3 B 43$ against ground rainfall. (a) NEM: Northeast monsoon, (b) IM1: Inter-monsoon 1, (c) SWM: Southwest monsoon, (d) IM2: Inter-monsoon 2.

\subsection{TRMM Seasonal Quantitative Error in Local Climate Regions}

The RMSE was higher during the wet seasons (NEM and IM2) (Figure 6) compared to the SWM and IM1 for all climate regions, except the northwest region during the NEM. The RMSE during the NEM and IM 2 contributed the largest proportion of the annual error, approximately $56 \%-61 \%$ for all regions. During the wettest part of the NEM, the range of RMSE was 120-162 mm, and it was mostly distributed in the east where rainfall was high (Figure 6). Consequently, temporal maps also showed that a high RMSE during the NEM (Figure 7a) occurred in the east including all the highlands in that region. During IM2, high RMSE values were concentrated mainly in the upper part of the Peninsula, which includes the northwest, upper part of the west, east, and northern highland regions (Figure 7d). No spatial distribution of RMSE during SWM and IM1 among regions was discernible (Figure 7b,c) with values of 80-100 mm/month. Significant seasonal rainfall differences were identified from the ground rainfall $\left(\mathrm{F}_{0.05} ; 3,3312=428\right)$. This indicates that occurrences of the large seasonal RMSE are associated with high rainfall during the NEM and IM (Figure 6). The cross-validation of the interpolated areal precipitation gridded product revealed that it increased linearly with the increment of seasonal rainfall (Table 3). The mean average error percentage ranged from $8 \%$ to $13 \%(13-22 \mathrm{~mm})$. This showed that the systematic error from the interpolation contributed a small portion of the uncertainty on the validation outcomes.

Table 3. Cross-validation on the high resolution areal interpolated precipitation.

\begin{tabular}{|c|c|c|c|c|}
\hline \multirow{2}{*}{ Monsoon Season } & \multicolumn{2}{|c|}{ Cross-Validation Metrics } & \multirow{2}{*}{$\begin{array}{c}\text { Average Ground } \\
\text { Rainfall (mm) }\end{array}$} & \multirow{2}{*}{$\begin{array}{c}\text { Percentage upon the } \\
\text { TRMM-RG RMSE }(\%)\end{array}$} \\
\hline & RMSE (mm) & MAPE (\%) & & \\
\hline NEM & 22 & 13 & 198 & 11 \\
\hline IM1 & 15 & 10 & 112 & 13 \\
\hline SWM & 13 & 8 & 118 & 11 \\
\hline IM2 & 20 & 11 & 171 & 12 \\
\hline
\end{tabular}




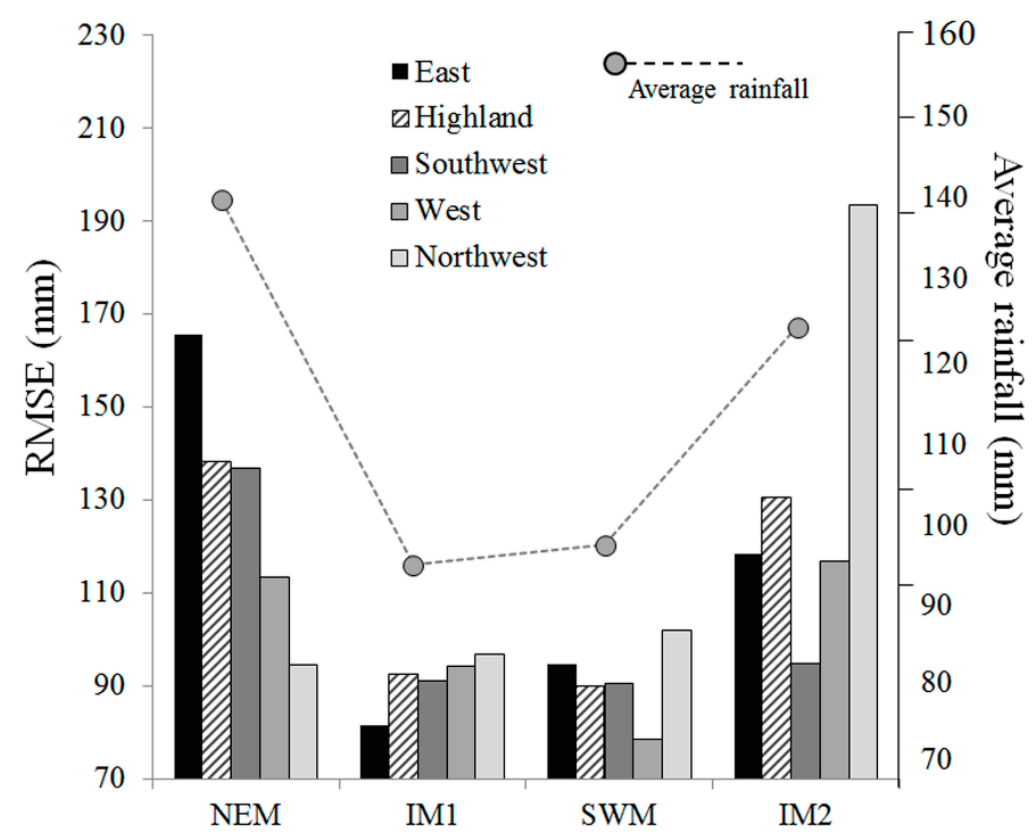

Figure 6. Average seasonal RMSE of the TRMM 3B43 against ground rainfall in local climate regions and average rainfall from areal rainfall surfaces for the period 1998-2010.
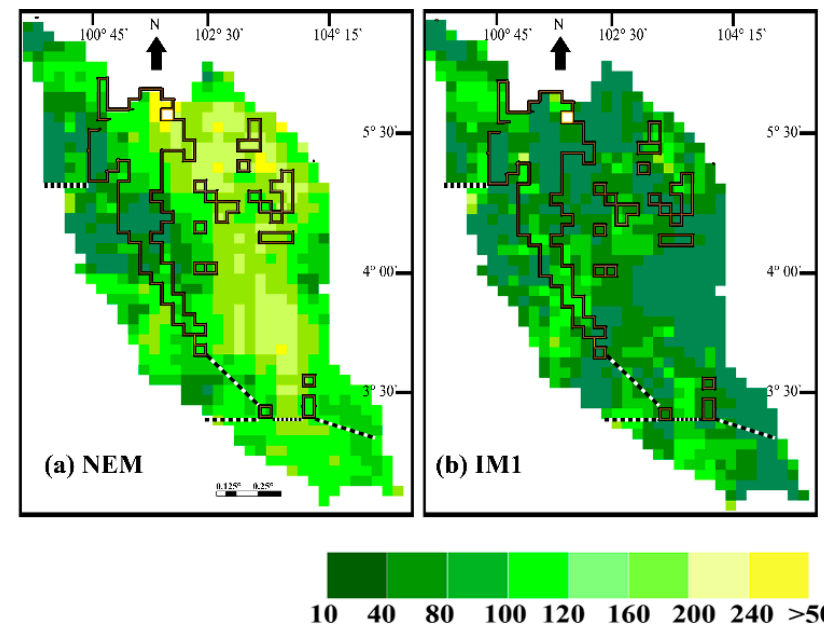

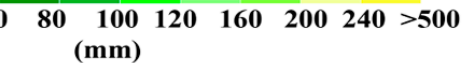

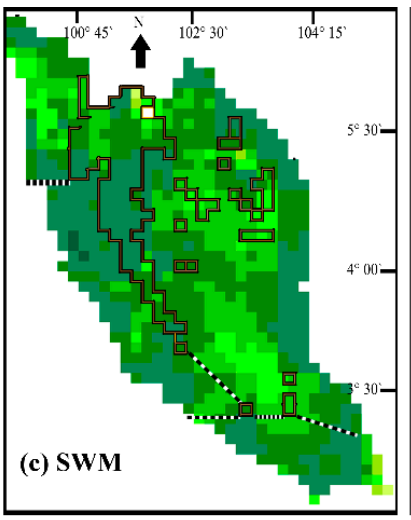

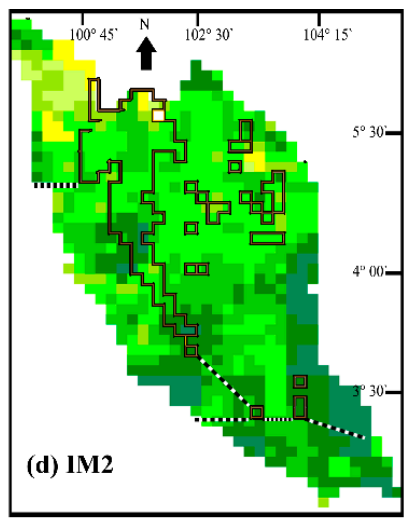

Highland

ıı... Local climate region boundary

Figure 7. Temporal maps of seasonal RMSE of the TRMM 3B43 against ground rainfall.

(a) NEM: Northeast monsoon, (b) IM1: Inter-monsoon 1, (c) SWM: Southwest monsoon, (d) IM2: Inter-monsoon 2.

\subsection{TRMM Seasonal Rainfall Amount Estimation in Local Climate regions}

Positive average ratio indicated that the TRMM overestimated the actual rainfall in all climate regions during all monsoon seasons (Figure 8). The variation of ratios varied among the regions, particularly between northwest, southwest and west. The average bias of the TRMM data can be ranked from low to high as follows: southwest $(30 \%-50 \%)$, highland $(60 \%-70 \%)$, east $(50 \%-100 \%)$, west $(70 \%-100 \%)$ and northwest $(120 \%-160 \%)$. In fact, the northwest area had a comparatively larger bias $(>200 \%)$ than the other regions during all respective monsoon seasons. A distinct overestimate was indicated during IM1 in the east region. Temporal maps depicted that TRMM has largely overestimated the ground rainfall in the northwest region every monsoon season (Figure 9). In addition, there were areas that 
experienced consistent satellite underestimation (green colors) (Figure 6a-d).Further investigation into those areas using digital elevation models revealed that it was the underlying terrain from areas with high elevation (Figure 10). This signifies that the ability of TRMM to represent the actual rainfall pattern was region-specific rather than seasonal.

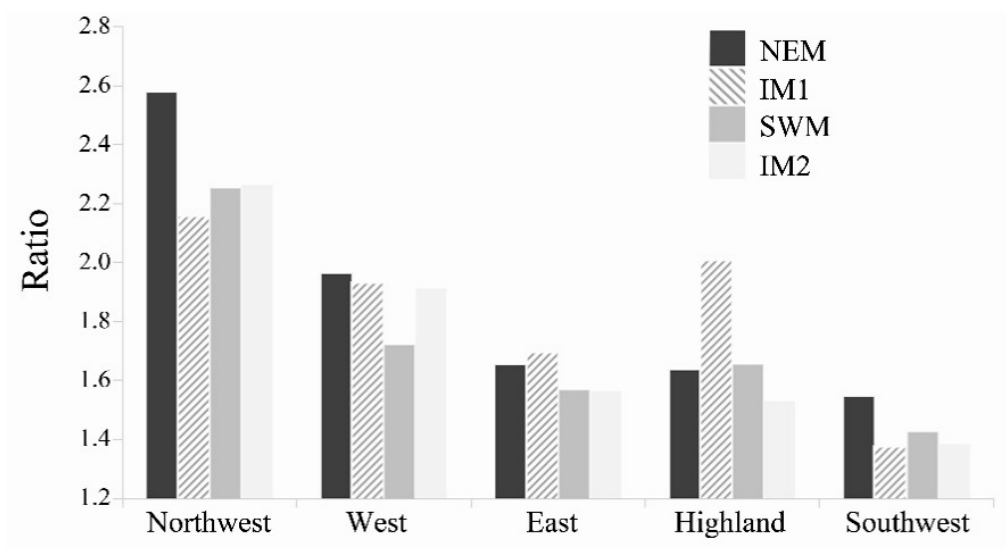

Figure 8. Average seasonal ratio values between TRMM rainfall estimates and ground rainfall in local climate regions.
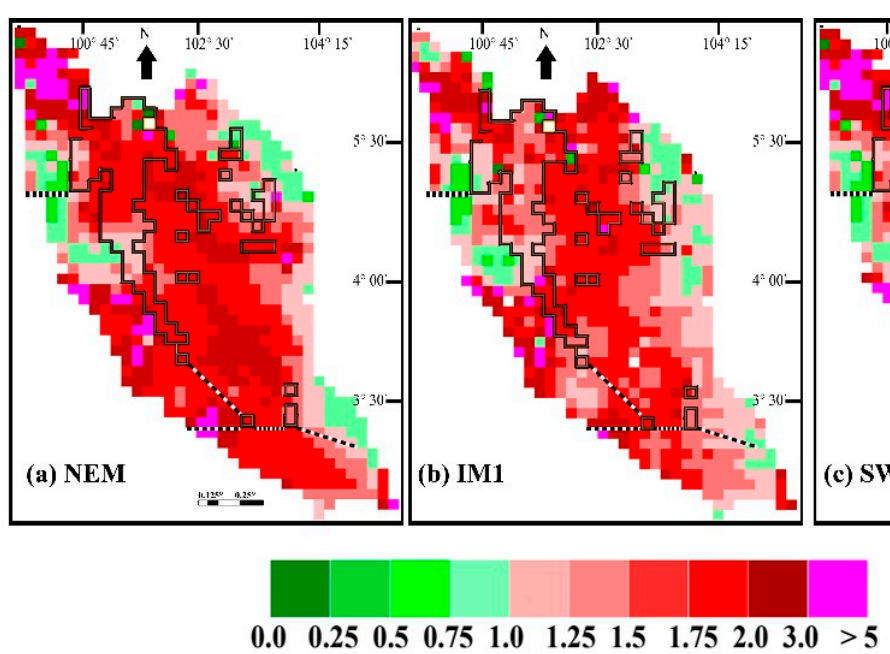

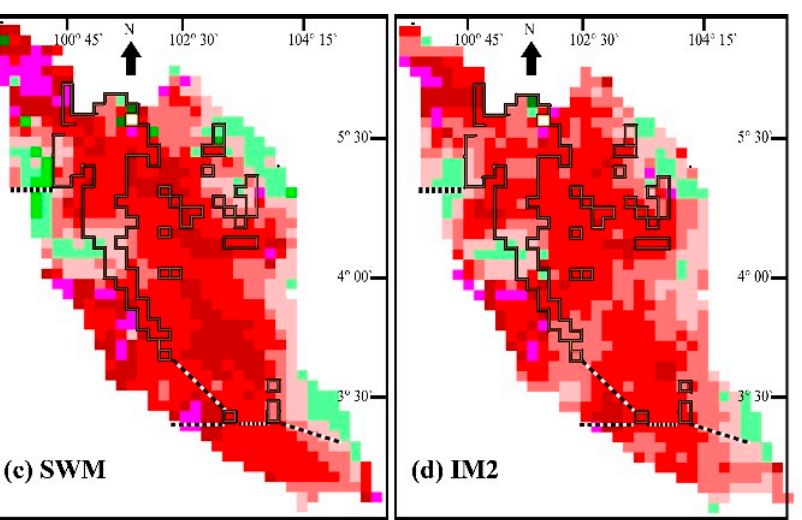

Highland

nu, Local climate region boundary

Figure 9. Temporal maps of seasonal ratios of the TRMM 3B43 over ground rainfall.

(a) NEM: Northeast monsoon, (b) IM1: Inter-monsoon 1, (c) SWM: Southwest monsoon, (d) IM2: Inter-monsoon 2.

\subsection{TRMM Seasonal Efficiency vs. the Rain Gauge Observations}

Figure 11 shows that the efficiency of TRMM varied within monsoon seasons. The average efficiency of TRMM was higher during the NEM (0.302) and IM1 (0.386) than during the SWM ( -0.188$)$ and IM2 $(-0.191)$. During the wettest and driest seasons of the NEM and IM1, respectively, TRMM proved to be more efficient. The trend towards a stronger seasonal than regional influence indicated that the seasonal co-efficient of variation (COV) of ground rainfall has largely influenced the TRMM efficiency. The efficiency differences that occurred within regions during the NEM and IM1 were larger compared to SWM and IM2. This suggests that the spatial rainfall COV during the wettest and driest seasons is the driving factor that determines the efficiency of TRMM. 


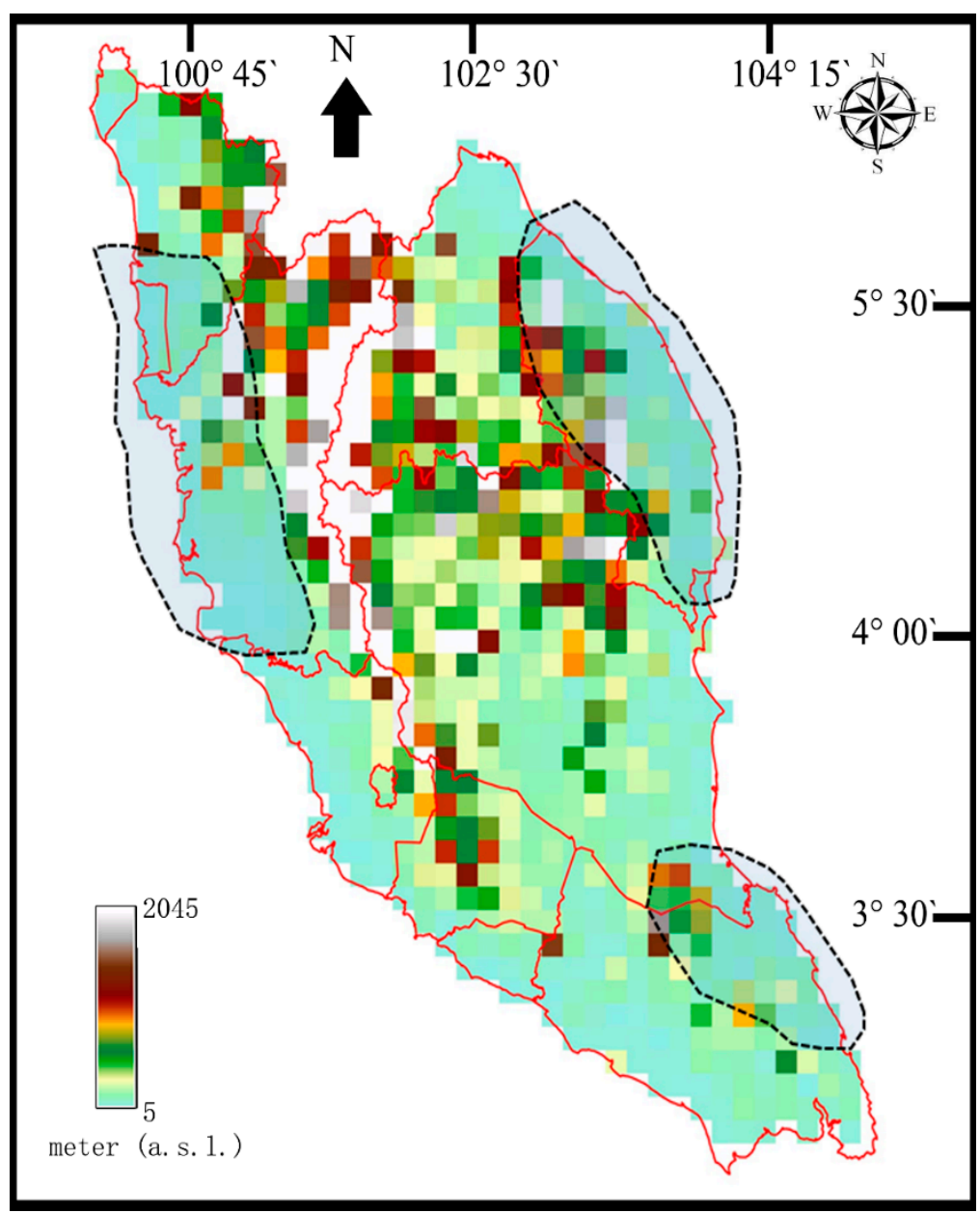

Figure 10. Areas experiencing consistent TRMM underestimations (dashed polygons). The elevation map is derived from re-gridded Shuttle Radar Topography Mission (SRTM) data at 0.125 degree resolution.

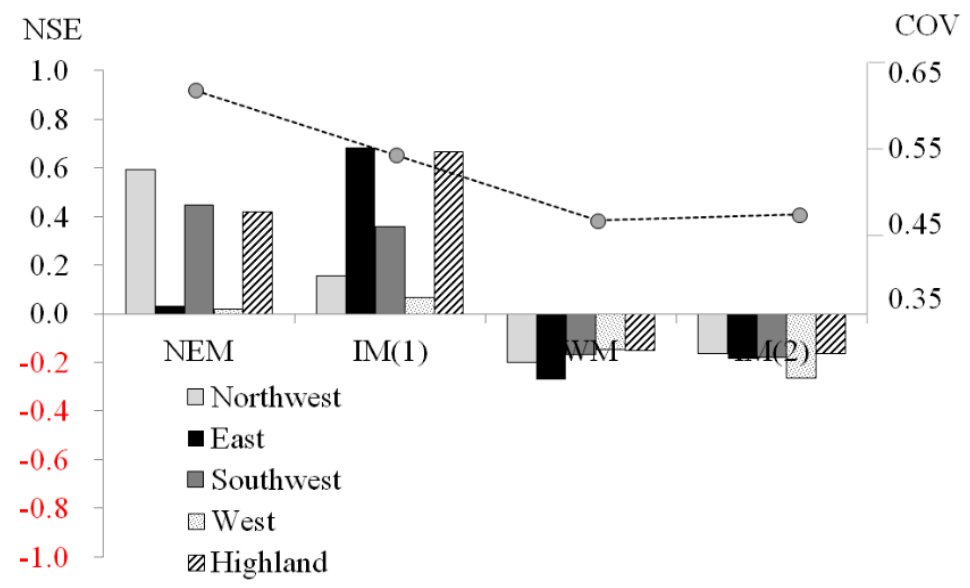

Figure 11. Average seasonal NSE of the TRMM 3B43 against ground rainfall in local climate regions and average rainfall from areal rainfall surfaces for the period 1998-2010.

\section{Discussion}

The seasonal scale validation of the TRMM precipitation data using a high-resolution areal precipitation grid for Peninsular Malaysia highlights the important characteristics of a small humid 
tropical basin in the equatorial region. In terms of temporal rainfall sensitivity, there were two major issues that needed to be investigated. The first was the weak correlation during the SWM and IM2, and the second was the large measurement error during the wet seasons of the NEM and IM2. From the perspective of an accurate representation of the seasonal spatial rainfall pattern, the TRMM sensitivity for each climate region must be improved, particularly in the northwest and west. These local scale seasonal uncertainties in Peninsular Malaysia were unique compared to the findings in a larger basin [29] and were unidentified by previous studies [9]. Downscaling the grid to a fine scale $\left(0.125^{\circ}\right)$ did not introduce drastic subgrid variation that affected the overall result, apart from the minimal impact on spatial variability during dry seasons. Since TRMM 3B43 monthly rainfall data product is not available in near real time [30] and the hydrological application had to use a less calibrated data product, our findings provide useful information as a reference and reflect its limitation at a local basin scale.

The seasonal correlated behavior that could have a relationship with a coefficient of variation can be explained by the presence of low and heavy precipitation clouds. A similar condition also occurred in the previous daily basis validation [9], and the effect found in this study could be the result of the longer temporal scale (hourly and daily to monthly). Because TRMM has better sensitivity towards heavy rather than low precipitation clouds, a good correlation was obtained during NEM. The majority of the heaviest rainfall during NEM was primarily caused by the large-scale monsoon flows that contained heavy precipitation cloud [21]. However, during SWM and IM2, in which both heavy and low precipitation clouds occurred, the correlation decreased due to insensitivity towards a low precipitation cloud.

A large measurement error (RMSE) of TRMM during the wet seasons has frequently been identified in humid tropical regions $[6,10,12,31]$. The major constituent was the effect of scaling up the instantaneous rain rate from an hourly to a monthly basis using the given scale factor. Other contributing factors were the temporal differences between TRMM and rain gauge measurements and the systematic error of interpolation. However, the effect of temporal differences was considered minimal, because the time mismatch was only $1 \mathrm{~h}$ ( $\sim 8.00-9.00$ am local time). From another perspective, the interpolation showed a linear effect towards increasing rainfall in a relatively small proportion. The RMSE in this study was relatively lower than in previous studies conducted in Southeast Asia using a similar data product. We clarified that the RMSE varied depending on seasonal rainfall intensity and method to calculate the cumulative monthly rainfall.

The TRMM spatial specific-region behavior might be influenced by two factors; the coarse initial grid size of the TRMM $\left(0.25^{\circ}\right)$ and the mechanism of precipitation measurement. The coarse initial TRMM grid size made it less sensitive to local scale rainfall patterns and distribution. Apart from the systematic error of the TRMM, the subgrid variation showed at $0.125^{\circ}$ that the TRMM data were unable to resolve the small-scale of the convective cloud distribution and its shorter temporal variation during the dry seasons. In addition, the insensitivity of the TRMM sensor algorithm towards those cloud characteristics can lead to miscalculation of the rain rate [32].Another plausible factor is the difference between precipitation measurement mechanisms of the satellite and rain gauge. In principle, satellite precipitation radar operates by estimating the rain rate in the atmosphere rather than by quantifying the actual rainfall on the ground [33]. Consequently, the TRMM has limited sensitivity for areas with a complex spatial rainfall pattern due to environmental parameters including the orography effect, monsoon flow, and distance to the sea, such as in the east region. 
The comparative efficiency of the TRMM vs. the ground areal rainfall showed that the seasonal effects were stronger than the regional effects. Prior to this, we suggested that TRMM sensitivity towards high and low precipitation clouds that influenced the seasonal correlation was more influential at determining the efficiency of the TRMM than the coarse grid size and difference in precipitation measurement mechanisms between satellite and rain gauges. Improving the seasonal scale performance during the SWM and IM2 is critical to obtaining high precision annual rainfall for our study site. This requires careful consideration and treatment of clouds with medium precipitation, which were common during this period.

Downscaling should attempt to resolve the uncertainties found in this study. The large error propagated during the wet seasons of IM2 and NEM will lead to inaccurate rainfall estimates that will affect quantitative rainfall estimates. In addition, the low seasonal correlation during the SWM and IM1 will lead to inaccurate temporal monsoon variation prediction from TRMM data. Temporal downscaling is recommended to improve both correlation and measurement differences. For the context of the Asian region, a procedure introduced by Yatagai et al. [34] and Ryo et al. [35] is scientifically sound. In terms of spatial rainfall variability, because the ability of TRMM to depict accurate spatial rainfall patterns varied within the local climate region, the use of spatial downscaling is recommended especially in the northwest and west regions.

However, there is a lack of spatial downscaling approaches adaptable to the humid tropics. Such a development would be an advance in satellite precipitation data downscaling. The use of an alternative satellite data product, such as CMORPH or GSMaP, which are effective in high elevations [36] as a substitute for TRMM or their integration, is a possible measure for deriving high precision precipitation. In short, downscaling satellite precipitation data to support local-scale hydrological applications is expected to be an active endeavor prior to the launch of the Global Precipitation Mission, the TRMM successor. Although this study used TRMM ver. 6, our findings provide useful, relevant information that can be applied to improve the subsequent versions of TRMM and its successor. The comparison between TRMM RT Version 7 datasets also showed no significant differences for this region (See Appendix).

\section{Conclusions}

This study validated the re-gridded TRMM 3B43 $\left(0.125^{\circ}\right)$ monthly rainfall estimates at seasonal monsoon scale at the local climate region of Peninsular Malaysia (1998-2010) using high resolution areal precipitation surfaces. The TRMM correlations varied seasonally and were high during the wettest period of the NEM $(0.63-0.8)$ and its transitional period of IM1 $(0.55-0.65)$ for all regions and decreased gradually over the remainder of the monsoon period. The ability of TRMM to estimate actual rainfall varied among local climatic regions and conditions were often overestimated; the extent of overestimation was $30 \%-50 \%$ in the southwest, $60 \%-70 \%$ in the highland region, $50 \%-100 \%$ in the east, $70 \%-100 \%$ in the west and $120 \%-160 \%$ in the northwest. The coarse grid size of the initial TRMM data has led to an insensitivity to local rainfall patterns that is strongly influenced by environmental factors and convective clouds. The quantitative errors (RMSE) were significantly related to the wet seasons in NEM and IM2.A large RMSE was identified in the east (120mm-NEM; 165mm-IM2), the highland region (130mm-NEM-140mm-IM2), and the northwest region (190mm-IM2) during both monsoon seasons. This study provides detailed spatial uncertainty patterns and variations of the direct 
spatial downscale of TRMM which served as a critical reference for further downscaling activities of the satellite precipitation data.

\section{Acknowledgments}

The authors would like to express their unending gratitude to the Tokyo Metropolitan Government for their support through the Asian Human Resources Doctoral Fellowship Program that made this research possible. Other significant thanks go to the Department of Irrigation and Drainage Malaysia, National Aeronautics and Space Administration (NASA), and the Technology University of Malaysia (UTM) for their support in contributing enormous amounts of data for this research.

\section{Author Contributions}

All authors contributed extensively to the work presented in this paper. Mohd Rizaludin Mahmud developed the concept, designed and implemented the experiment and wrote the manuscript. Mazlan Hashim provides in-situ observation data, technical support and conceptual advice. Shinya Numata, Tetsuro Hosaka and Hiroshi Matsuyama supervised the experiment design, analysis and edited the manuscript. All authors discussed the results and implications on the manuscript at all stages.

\section{Conflicts of Interest}

The authors declare no conflict of interest.

\section{Appendix}

Table A1. Average monthly rainfall differences derived from TRMM 3B43 version 6 and 7 for Peninsular Malaysia from 1999 to 2001.

\begin{tabular}{ccccc}
\hline \multirow{2}{*}{ Monsoon Seasons } & \multicolumn{5}{c}{ Monthly Difference (\%) } \\
\cline { 2 - 5 } & $\mathbf{1 9 9 9}$ & $\mathbf{2 0 0 0}$ & $\mathbf{2 0 0 1}$ & Average \\
\hline NEM & 10 & 8 & 6 & 8 \\
IM1 & 14 & 12 & 11 & 12 \\
SWM & 7 & 7 & 10 & 8 \\
IM2 & 5 & 6 & 11 & 7 \\
\hline
\end{tabular}

Table A2. $T$-test result of the TRMM 3B43 version 6 with version 7 for each corresponding monsoon seasons in every region.

\begin{tabular}{|c|c|c|c|c|c|c|c|c|c|c|c|c|c|c|c|}
\hline \multirow[t]{2}{*}{ Monsoon season/ Years } & \multicolumn{5}{|c|}{1999} & \multicolumn{5}{|c|}{2000} & \multicolumn{5}{|c|}{2001} \\
\hline & $\mathrm{N}$ & $\mathrm{E}$ & $\mathrm{W}$ & $\mathrm{S}$ & $\mathrm{H}$ & $\mathrm{N}$ & $\mathrm{E}$ & $\mathrm{W}$ & $\mathrm{S}$ & $\mathrm{H}$ & $\mathrm{N}$ & $\mathrm{E}$ & $\mathrm{W}$ & S & $\mathrm{H}$ \\
\hline NEM & ns & ns & ns & ns & ns & ns & ns & ns & ns & ns & ns & ns & ns & ns & ns \\
\hline IM1 & ns & ns & ns & ns & ns & ns & ns & ns & ns & ns & ns & ns & ns & ns & ns \\
\hline SWM & ns & ns & ns & ns & ns & ns & ns & ns & ns & ns & ns & ns & ns & ns & ns \\
\hline IM2 & ns & ns & $\mathrm{ns}$ & ns & ns & $\mathrm{ns}$ & $\mathrm{ns}$ & ns & ns & ns & ns & ns & ns & ns & $\mathrm{ns}$ \\
\hline
\end{tabular}


Year (1999)
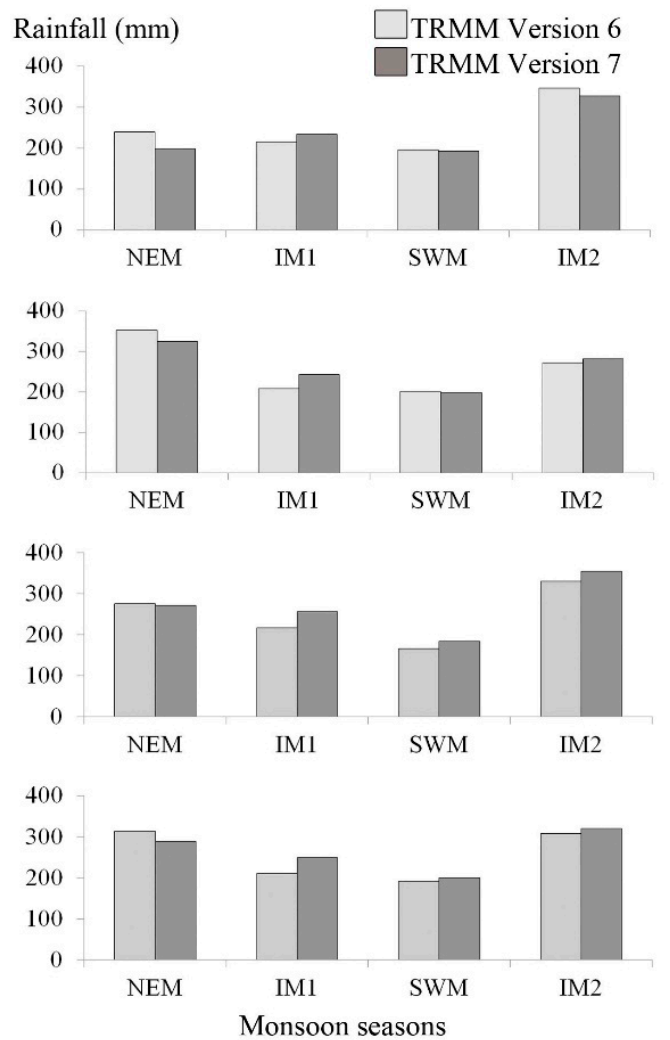

Year (2000)
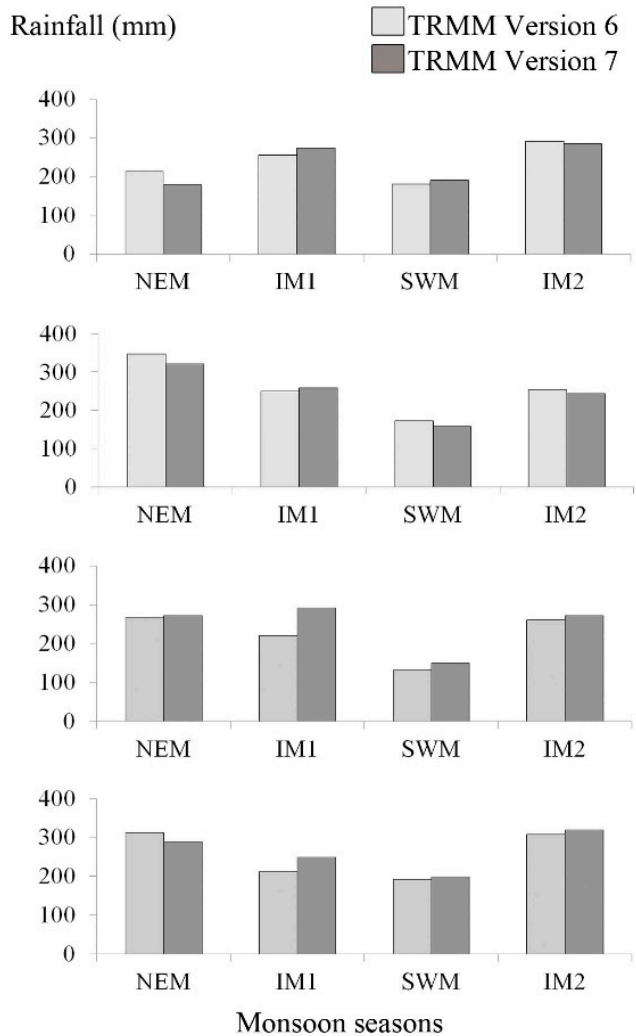

Year (2001)
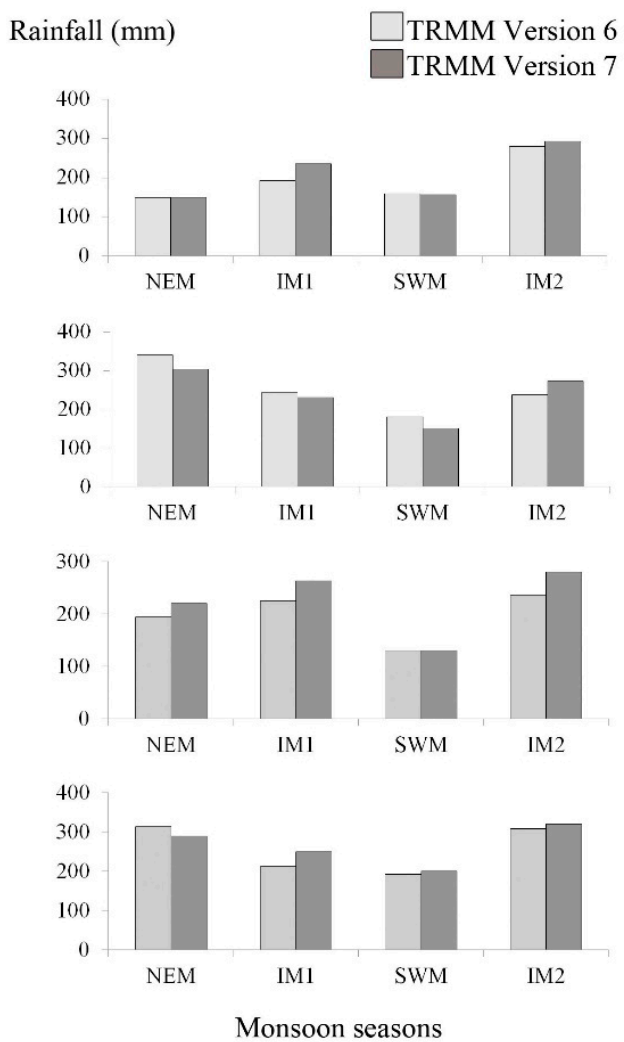

Figure A1. Average monthly rainfall derived from TRMM 3B43 version 6 and 7 for Peninsular Malaysia from 1999 to 2001. 


\section{References}

1. Wilby, R.L.; Yu, D. Rainfall and temperature estimation for a data sparse region. Hydrol. Earth Syst. Sci. 2013, 17, 3937-3955.

2. De Paiva, R.C.; Buarqe, C.; Collischonn, W.; Bonnet, M.; Frappart, F.; Calmant, S.; Mendes, B. Large-scale hydrologic and hydrodynamic modeling of the Amazon River basin. Water Resour. Res. 2013, 49, 1226-1243.

3. Krakauer, N.Y.; Pradhanang, S.M.; Lakhankar, T.; Jha, A.K. Evaluating satellite products for precipitation estimation in mountain regions: A case study for Nepal. Remote Sens. 2013, 5, 4107-4123.

4. Islam, M.N.; Uyeda, H. Use of TRMM in determining the climatic characteristics of rainfall over Bangladesh. Remote Sens. Environ. 2007, 108, 264-276.

5. Li, X.H.; Zhang, Q.; Xu, C. Suitability of the TRMM satellite rainfalls in driving a distributed hydrological model for water balance computations in Xinjiang catchment, Poyang lake basin. J. Hydrol. 2012, 426, 28-38.

6. Franchito, S.H.; Rao, V.B.; Vasques, A.C.; Santo, C.M.E.; Conforte, J.C. Validation of TRMM precipitation radar monthly rainfall estimates over Brazil. J. Geophy. Res. 2009, 114, 1-9.

7. Almazroui, M. Calibration of TRMM rainfall climatology over Saudi Arabia during 1998-2009. Atmos. Res. 2011, 99, 400-414.

8. Roongroj, C.; Long, S.C. Thailand daily rainfall and comparison with TRMM products. J. Hydrometeorol. 2008, 9, 256-266.

9. Varikoden, H.; Samah, A.A.; Babu, C.A. Spatial and temporal characteristics of rain intensity in the Peninsular Malaysia using TRMM rain rate. J. Hydrol. 2010,387, 312-319.

10. Prasetia, R.; As-syakur, A.R.; Osawa, T. Validation of TRMM precipitation radar satellite data over Indonesian region. Theor. Appl. Climatol. 2013, 112, 575-587.

11. Mahmud, M.R. Run-off Modeling and Mapping Using Rainfall and Evapotranspiration Estimates from Remote Sensing Satellite Data in Peninsular Malaysia; Universiti Teknologi Malaysia: Johor Bharu, Malaysia, 2011.

12. Collischonn, B.; Collischonn, W.; Tucci, C.E.M. Daily hydrological modeling in the Amazon Basin using TRMM rainfall estimates. J. Hydrol. 2008, 360, 207-216.

13. Behrangi, A.; Khakbaz, B.; Jaw, T.C.; AghaKouchak, A.; Hsu, K.; Sorooshian, S. Hydrologic evaluation of satellite precipitation products over a mid-size basin. J. Hydrol. 2011, 360, 225-237.

14. Mahmud, M.R., Hashim, M. Operational Satellite-Based Watershed Monitoring Systems (SAWMOS) for Large Humid Tropical Catchment Environment; IEEE Colloquium on Humanities, Science and Engineering (CHUSER): Penang, Malaysia, 2011; pp.687-691.

15. Park, N.-W. Spatial downscaling of TRMM precipitation using geostatistics and fine scale environmental variables. Adv. Meteorol. 2013, 2013, 1-8.

16. Tao, K.; Barros, P. Using fractal downscaling of satellite precipitation products for hydrometeorological applications. J. Atmos. Ocean. Tech. 2010, 27, 409-427.

17. Omotosho, T.V.; Mandeep, J.S.; Abdullah, M.; Adejiji, A.T. Distribution of one-minute rain rate in Malaysia derived from TRMM satellite data. Ann. Geophys. 2013, 31, 2013-2022.

18. Adeyewa, Z.D.; Nakamura, K. Validation of TRMM radar rainfall data over major climatic regions in Africa. J. Appl. Meteorol. 2003, 42, 331-347. 
19. Nicholson, S.E.; Some, B.; McCollumn, J.; Nelkin, E.; Klotter, D.; Berte, Y.; Diallo, B.M.; Gaye, I.; Kpabeba, G.; Ndiaye, O.; et al. Validation of TRMM and other rainfall estimates with high-density gauge dataset for West Africa. Part II; Validation of TRMM rainfall products. J. Appl. Meteorol.2003, 42, 1337-1354.

20. Wong, C.L.; Venneker, R.; Uhlenbrook, S.; Jamil, A.B.M.; Zhou,Y. Variability of rainfall in Peninsular Malaysia. Hydrol. Earth Syst. Sci. Discuss. 2009, 6, 5471-5503.

21. Cheang, B.K.Some Aspects of Winter Monsoon and Its Characteristics in Malaysia; Malaysian Meteorological Service: Jalan Sultan, Petaling Jaya, Selangor, Malaysia, 1980.

22. Varikoden, H.; Preethi, B.; Samah, A.A.; Babu, C.A. Seasonal variation of rainfall characteristics in different intensity classes over Peninsular Malaysia. J. Hydrol. 2011, 404, 99-108.

23. Vegas-Vilarrubia, T.; Maass, M.; Rull, V.; Vaclavelias Ramon, A.; Ovalle, C.; Lopez, D.; Schneider, G.; Depetris, P.J.; Douglas, I. Small catchment studies in the tropical zone. In Biogeochemistry of Small Catchments: A Tool for Environmental Research; Moldan, B., Cerny, J., Eds.; John Wiley \& Sons Ltd.: Hoboken, NJ, USA,1994; pp. 343-360.

24. Hou, A.Y.; Kakar, R.K.; Neeck, S.; Azarbazin, A.A.; Kummerow, C.D.; Kojima, M.; Oki, R.; Nakamura, K.; Iguchi, T. The Global Precipitation Measurement Mission. Bull. Amer. Meteor. Soc. 2014, 95, 701-722.

25. Satellite Image Atlas of Malaysia, an Atlas of Satellite Imagery; Malaysian Centre for Remote Sensing \&Universiti Teknologi Malaysia: Kuala Lumpur, Malaysia, 2008.

26. Dale, W.L. The rainfall of Malaya. J. Tropical Geogr.1959, 13, $23-37$.

27. TRMM Precipitation Radar Team, Japan Aerospace Exploration Agency, National Aeronautics and Space Administration. Tropical Rainfall Measuring Mission Precipitation Radar Algorithm Instruction Manual for Version 6; Japan Aerospace Exploration Agency (JAXA): Tokyo, Japan, 2005.

28. Mair, A.; Fares, A. Comparison of rainfall interpolation methods in a mountainous region of a tropical island. J. Hydrol. 2011, 16, 371-383.

29. Clarke, R.T.; Buarqe, D.C.; de Paiva, R.C.; Collischonn, W. Issues of spatial correlation arising from the use of TRMM rainfall estimates in the Brazilian Amazon. Water Resour. Res. 2011, 47, doi: 10.1029/2010WR010334.

30. Liu, Z.; Ostrenga, D.; Teng, W.; Kempler, S.; Milich, L. Developing GIOVANNI-based online prototypes to intercompare TRMM-related global gridded-precipitation products. Comput. Geosci. 2014, 66, 168-181.

31. Su, F.; Hong, Y.; Lettenmaier, D.P. Evaluation of TRMM Multisatellite Precipitation Analysis (TMPA) and its utility in hydrologic prediction in the La Plata basin. J. Hydrometeorol. 2007, 9, 622-640.

32. Wolf, D.B.; Marks D.A.; Amital, E.; Silberstein, D.S.; Fisher, B.L.; Tokay A.; Wang J.; Pippitt, J.L. Ground validation for the Tropical Rainfall Measuring Mission (TRMM). J. Atmos. Ocean. Tech. 2005, 22, 365-380.

33. Iguchi, T.; Kozu, T.; Meneghini, R.; Awaka, J.; Okamoto, K. Rain-profiling algorithm for the TRMM precipitation radar. J. Appl. Meteorol. 2000, 39, 2038-2052.

34. Yatagai, A.; Krishnamurti, T.N.; Kumar, V.; Mishra, A.K.; Simon, A. Use of APHRODITE rain gauge-based precipitation and TRMM 3B43 products for improving Asian monsoon seasonal precipitation forecasts by the superensemble method. J. Clim. 2014, 27, 1062-1069. 
35. Ryo, M.; Valeriano, O.C.S.; Kanae, S.; Ngoc, T.N. Temporal downscaling of daily gauged precipitation by application of a satellite product for flood simulation in a poorly gauged basin and its evaluation with multiple regression analysis. J. Hydrometeorol. 2014, 15, 563-580.

36. Dinku, T.; Ceccato, P.; Grover-Kopec, E.; Lemma, M.; Connor, S.J.; Ropelewski, C.F. Validation of satellite rainfall products over East Africa's complex topography. Int. J. Remote Sens. 2007, 28, $1503-1526$.

(C) 2015 by the authors; licensee MDPI, Basel, Switzerland. This article is an open access article distributed under the terms and conditions of the Creative Commons Attribution license (http://creativecommons.org/licenses/by/4.0/). 